\title{
The Relation of Critical Thinking Disposition, Nursing Professional Values, and Satisfaction in Clinical Practice of Nursing Students
}

\author{
Gyung Park \\ Nursing Department, Mokpo Catholic University, Korea \\ gypark@mcu.ac.kr
}

\begin{abstract}
The purpose of the study is to certify factors that affect Satisfaction in Clinical Practice and the relation among Critical Thinking Disposition, Nursing Professional Values, and of nursing college students. The research used with the structured questionnaire is a descriptive research of fourth-grade undergraduates in nursing departments at two universities. For collected data analysis, using SPSS/WIN 22.0. Differences in Critical Thinking Disposition, Nursing Professional Values, and Satisfaction with Clinical Practice according to the general characteristics of the subjects were analyzed using t-tests, ANOVA, and the Schéffe test was applied for post-validation purposes, Pearson's correlation coefficients, and Multiple regression analysis. As a result, Satisfaction in the Clinical Practice of nursing college students indicated the existence of a significant static correlation between Critical Thinking Disposition and Nursing Professional Values. And significant static correlations were found between Critical Thinking Disposition and Nursing Professional Values. Factors influencing Satisfaction in Clinical Practicing showed Nursing Professional Values and religion.
\end{abstract}

Keywords: Nursing college student, Critical thinking disposition, Nursing professional values, Satisfaction in clinical practice

\section{Introduction}

The purpose of nursing education is to educate capable nurses with extensive and holistic nursing knowledge, experience, skills, and strong nursing values through not only theoretical education but clinical practice [1]. In particular, clinical practice education is a prerequisite course in which nursing college students improve their competence to settle integrated and systematic nursing problems from the perspective of the patient, not fragmented skill experience, and learn the attitude of professional nurses [2]. One of the indicators to confine whether the purpose of education has been accomplished is Satisfaction in Clinical Practice, and when nursing student's Satisfaction in Clinical Practice is high, clinical practice can be performed with autonomy and responsibility, maximizing the effect of clinical practice training, and demand to actively plan for nursing professionals [3].

In the rapidly changing healthcare environment to cope with various clinical situations, critical thinking is demanded of nurses, which is an important element of nurses' professional responsibility and quality nursing performance. Critical thinking is a cognitive process [4] that occurs throughout the problem-solving and decision-making process, discerning what is

Article history:

Received (March 28, 2019), Review Result (April 29, 2019), Accepted (May 30, 2019) 
important and attempting to use it if any. It is reported as a key factor that positively affects the ability to solve problems and perform properly in a situation [5][6].

Furthermore, to efficiently perform the task as a professional nurse in a decision-making process to solve the problems encountered in various and complex clinical fields it is required to establish Nursing Professional Values.

Proceeding studies, nursing professionalism is a conscious view with systematic opinions on nursing, nursing activity, and professionalism, the more positive the Nursing Professional Values is, the higher the job satisfaction and the lower the turnover rate, and forming the correct attitude to the task performance so that effective nursing work is achieved [7].

The Korean Accreditation Board of Nursing Education also emphasizes nursing professional values as an indicator of the educational accomplishment of nursing students [8]. Because nursing students experience practical work in the clinical field and form the values of the nursing professional [3], schools and clinical practice education institutions need to aim at career socialization after graduation [9] by encouraging students to get desirable Nursing Professional Values.

Therefore, the purpose of the research is to verify the relationship between Satisfaction in Clinical Practice Nursing Professional Values and the Critical Thinking Disposition of nursing college students and certify the factors influencing Satisfaction in Clinical Practice and make offer basic data for preparing measures for efficient clinical practice education.

\section{Study method}

\subsection{Design of the study}

The study is descriptive survey research designed to verify the Satisfaction in clinical practice, Nursing professional values, Critical thinking disposition, and of nursing college students.

\subsection{Subjects of the study}

Subjects of the study understood the goal of the study and agreed to participate in the study among undergraduate nursing college students at two universities in one province. The sample size required to achieve an effect size $=$ of .15 , significance level $=$ of .05 , and power anaysis $=$ of .95 was 178 by $\mathrm{G}^{*}$ Power 3.1. However, 290 copies were distributed and 281 copies were analyzed.

\subsection{Instrument of the study}

\subsubsection{Critical thinking disposition}

Critical Thinking Disposition was measured by the surveying tools of 27 questions developed by Yoon [10]. Each question was measured from 'not at all' 1-point to 'very much' 5-point on the five-point Likert scale, and two negative questions were inverted. The higher the score, the higher the Critical Thinking Disposition. It was Cronbach's $\alpha=.84$ of the tool at the time of development and in the study Cronbach's $\alpha=.81$.

\subsubsection{Nursing professional values}

It was measured with 18 questions out of 29 questions developed by Yeun [10] and reduced by Han [7] for the verification of the construct validity through a factorial analysis 
each question was measured from 'not at all' 1-point to 'very much' 5-point on the five-point Likert scale, and two negative questions were inverted. The higher the total score, the higher the nursing professional values. In Han Sang-sook et al [7]'s study it was Cronbach's $\alpha=.91$, in the study Cronbach's $\alpha=.86$.

\subsubsection{Satisfaction in clinical practice}

It was measured using the tools originally developed by Cho and Kang [11] and modified and supplemented to 31 questions by Lee et al. [12]. Each question was measured from 'not at all' 1-point to 'very much' 5-point on the five-point Likert scale, and two negative questions were inverted. The higher the total score, the higher the satisfaction in clinical practice. It was Cronbach's $\alpha=.89$ in the study of Lee et al [12] and Cronbach's $\alpha=.85$ in this study.

\subsection{Data collection and method}

Data were collected at two universities in one province from May 16 to May 23, 2018, with a structured questionnaire to an undergraduate nursing student who understood the purpose of the study and agreed to participate in the study. Before the survey, the researcher explained the purpose of the study, that the collected data would be treated anonymously and would be used for research purposes, and that they could be withdrawn at any time if they did not wish to. It took about 20 minutes to complete the questionnaire, and 281 copies were used for final data analysis, except for nine copies of the collected data, which were poorly answered in a total of 290 copies.

\subsection{Data analysis}

The collected data were analyzed by the SPSS/WIN 22.0 Program as below:

The differences in Critical Thinking Disposition, Nursing Professional Values, and Satisfaction in Clinical Practice according to the general characteristics of the subjects were used t-test, ANOVA, and Schéffe test.

The correlations of Satisfaction in Clinical Practice, Nursing Professional Values, and Critical Thinking Disposition of subjects were used by Pearson's correlation coefficients.

Multiple regressions were used to verify factors that affect the Satisfaction in Clinical Practice of the subjects.

\section{Research finding}

3.1. Differences in critical thinking disposition, nursing professional values, and satisfaction in clinical practice according to general characteristics of subjects

There were significant differences in Critical Thinking Disposition according to general characteristics appeared in gender $(\mathrm{t}=-2.293, \mathrm{p}=.023)$, major Satisfaction $(\mathrm{F}=8.207, \mathrm{p}<.001)$, and working role model $(\mathrm{t}=2.948, \mathrm{p}=.004)$. Nursing Professional Values according to general characteristics showed significant differences in application motivation $(\mathrm{F}=4.325 \mathrm{p}=.005)$, Satisfaction in Clinical Practice $(\mathrm{F}=4.021, \mathrm{p}=.019)$, a role model in practice $(\mathrm{t}=2.014$, $\mathrm{p}=.045$ ), whilst Satisfaction in Clinical Practice according to general characteristics showed significant differences in religion $(\mathrm{t}=2.233, \mathrm{p}=.026)$, satisfaction on nursing $(\mathrm{F}=4.727$, $\mathrm{p}=.010)$ and role model in practice $(\mathrm{t}=2.565, \mathrm{p}=.011)$ [Table 1].

Posteriori analysis showed that the Critical Thinking Disposition was significantly higher in "satisfied" than "moderate" and "dissatisfied" in satisfaction with nursing, while the 
Professionalism in Nursing had significantly higher in "aptitude" than "recommendation of parents or others", and the Satisfaction in Clinical Practice presented significantly higher in "satisfied" than "dissatisfied" in terms of satisfaction on nursing.

Table 1. Differences in critical thinking disposition, nursing professional values, and satisfaction in clinical practice $(\mathrm{N}=281)$

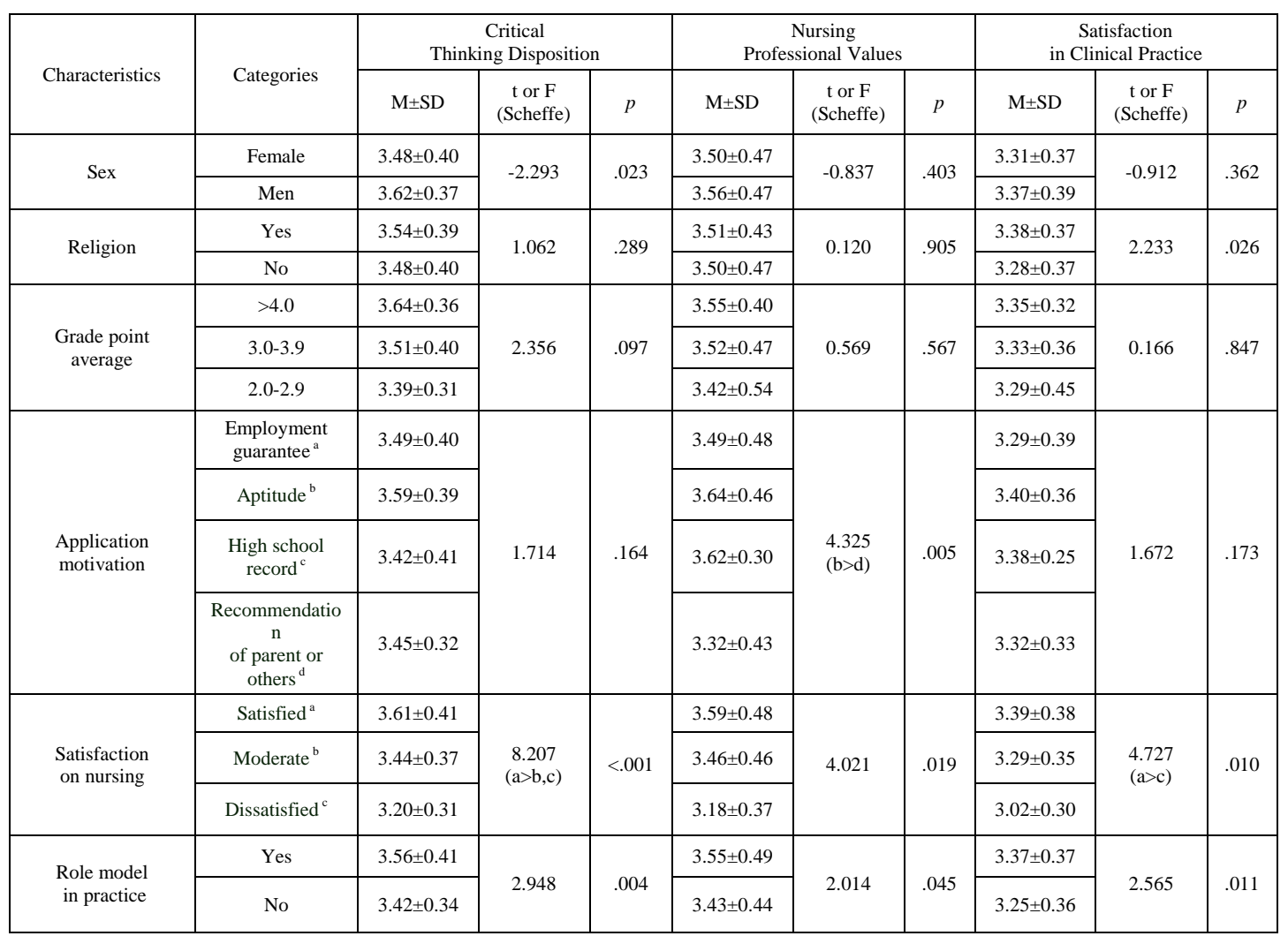

3.2. Correlations of critical thinking disposition, nursing professional values, and satisfaction in clinical practice of subjects

Satisfaction in clinical practice of subjects indicated the existence of significant static correlations between Critical Thinking Disposition ( $\mathrm{r}=.215, \mathrm{p}<.001)$ and Nursing Professional Values $(\mathrm{r}=.308, \mathrm{p}<.001)$, and both Critical Thinking Disposition and Nursing Professional Values had also significant $(\mathrm{r}=.280, \mathrm{p}<.001)$ [Table 2].

\subsection{Factors influencing satisfaction in clinical practice of the subject}

Based on the analysis of the influencing factors on Satisfaction in Clinical Practice, it is shown that Nursing Professional Values $(\beta=.268, \mathrm{t}=4.561, \mathrm{p}<.001)$ and religion $(\beta=-.114, \mathrm{t}=-$ 2.035, $\mathrm{p}=.043)$ Regression model showed statistical significant $(\mathrm{F}=9.062, \mathrm{p}<.001)$, and the model's explanatory power was $12.6 \%$ [Table 3]. 
Table 2. Correlation between critical thinking disposition, nursing professional values, and satisfaction in clinical practice of subjects $(\mathrm{N}=281)$

\begin{tabular}{|c|c|c|c|}
\hline Variables & $\begin{array}{c}\text { Critical } \\
\text { Thinking Disposition }\end{array}$ & $\begin{array}{c}\text { Nursing } \\
\text { Professional Values } \\
\mathrm{r}(\mathrm{p})\end{array}$ & $\begin{array}{c}\text { Satisfaction } \\
\text { in Clinical Practice } \\
\mathrm{r}(\mathrm{p})\end{array}$ \\
\hline Critical Thinking Disposition & 1 & $.280(<.001)$ & $.215(<.001)$ \\
\hline $\begin{array}{c}\text { Nursing Professional Values } \\
\text { Satisfaction in Clinical } \\
\text { Practice }\end{array}$ & - & 1 & $.308(<.001)$ \\
\hline
\end{tabular}

Table 3. Factors influencing on satisfaction in clinical practice of subjects $(\mathrm{N}=281)$

\begin{tabular}{|c|c|c|c|c|c|c|c|c|}
\hline Variables & $\mathrm{B}$ & $\mathrm{SE}$ & $\beta$ & $\mathrm{t}(\mathrm{p})$ & $\begin{array}{c}\text { Durbin- } \\
\text { Watson }\end{array}$ & $\mathrm{R} 2$ & $\begin{array}{c}\text { Adj } \\
\mathrm{R} 2\end{array}$ & $\mathrm{~F}(\mathrm{p})$ \\
\cline { 1 - 6 } Constant & 79.799 & 8.195 & & $9.735(<.001)$ & & & & \\
\cline { 1 - 5 } professional values & .344 & .079 & .256 & $4.361(<.001)$ & 1.961 & .141 & .126 & $\begin{array}{c}9.062 \\
(<.001)\end{array}$ \\
\cline { 1 - 5 } Religion & -2.639 & 1.297 & -.114 & $-2.035(.043)$ & & & \\
\hline
\end{tabular}

\section{Conclusion}

The study has attempted to verify the Critical Thinking Disposition, Nursing Professional Values, and Satisfaction in Clinical Practice of nursing college students and check the factors of Satisfaction in Clinical Practice to provide nursing students with basic data for preparing efficient clinical practice education methods.

Based on the analysis of the relations of three variables of nursing students, Satisfaction in Clinical Practice showed a significant static correlation with Critical Thinking Disposition and Nursing Professional Values. Nursing Professional Values and Critical Thinking Disposition appeared the existence of significant static correlations likewise. Given that Satisfaction in Clinical Practice is highly relevant to Critical Thinking Disposition and Nursing Professional Values, it is deemed necessary to consider how these variables will be reflected in theoretical and practical training courses.

Based on the analysis of influential factors of satisfaction in clinical practice, it turned out that nursing professionalism and religion significantly influence Satisfaction in Clinical Practice, the model's explanatory power was $12.6 \%$.

Considering the above and preceding studies, there is no doubt that Satisfaction in the Clinical Practice of nursing students is connected to nursing professionalism. Therefore, it is believed that the Satisfaction in Clinical Practice of nursing students can be enhanced if the intervention and education programs to form nursing professional values are developed and applied appropriately.

\section{Acknowledgments}

Satisfaction in clinical practice appeared the existence a significant positive correlation between nursing professional values and critical thinking disposition and nursing professional values and religion significantly influence satisfaction in clinical practice. In light of these 
findings, diverse variables that affect satisfaction in clinical practice shall be identified through repetitive research with expanded subjects.

\section{References}

[1] M.S. Kim, "Moderate effect of self-esteem and self-efficacy in the relationship between professional selfconcept and satisfaction in their major among nursing students," The Journal of the Korean Academic Society of Nursing Education, vol.17, no.2, pp.159-167, (2011)

[2] K.E. Kim and B.Y. Lee, "The relationship between satisfaction with clinical performance ability for nursing students," The Journal of Korea Contents Association, vol.14, no.10, pp.885-896, (2014)

[3] N.Y. Yang and S.Y. Moon, "Relationship of self-leadership, stress, and satisfaction in clinical practice of nursing students," Journal of Korean Academy of Nursing Administration., vol.17, no.2, pp.219-225, (2011)

[4] N.C. Facione, P.A. Facione, and C.A. Sanchez, "Critical thinking disposition as a measure of competent clinical judgment: The development of California thinking disposition inventory," Journal of Nursing Education, vol.33, no.8, pp.345-350

[5] J.Y. Lee and M.H. Cho, "Correlation between self-leadership, critical thinking disposition and problemsolving process in a diploma nursing students," Journal of Korean High Vocational Education Association, vol.13, no.34, pp.241-253, (2012)

[6] S.A. Yang, "Critical thinking disposition and problem-solving ability in nursing students," Journal of Korean Academy of Nursing Administration, vol.16, no.4, pp.389-398, (2012)

[7] S.S. Han, M.H. Kim, and E.K. Yun, "Factors Affecting Nursing Professionalism," The Journal of Korean Academic Society of Nursing Education., vol.14, no.1, pp.73-79, (2008)

[8] H.J. Park, "Correlations among nursing professionalism, critical thinking disposition and self-leadership in nursing students," The Journal of Korean Academic Society of Nursing Education, vol.21, no.2, pp.227-236, (2015)

[9] L.D. Karen and M.K. Anne, "A comparison of the professional nursing values of students, New graduates, and seasoned professionals," Nursing Education Research, vol.30, no.5, pp.279-284, (2009)

[10] E.J. Yeun, Y.M. Kwon, and O.H. Ahn, "Development of a nursing professional value scale," Journal of Korean Academy of Nursing, vol.35, no.6, pp.1091-1100, (2005)

[11] K.J. Cho and H.S. Kang, "Study on self-concept and satisfaction of clinical practice," Journal of Korean Academy of Nursing, vol.14, no.2, pp.63-74

[12] S.H. Lee, S.Y. Kim, and J.A. Kim, "Nursing Students` Image of Nurse and Satisfaction with Clinical Practice," The Journal of Korean Nursing Administration Academic Society, vol.10, no.2, pp.219-231, (2004)

\section{Authors}

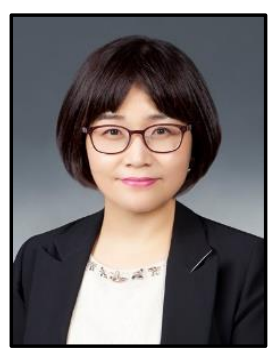

Gyung, Park

Doctor of Nurse science, Chonnam National University Graduate School, Gwangju, Korea, Professor of Mokpo Catholic University 